\title{
E27 Duya Sahip Lambaların Karşılaştırması için Test Düzeneği Hazırlanması
}

\author{
Sertaç GÖRGÜLÜ (D) 1*, Bahtiyar USLU (D)2 \\ ${ }^{1}$ Burdur Mehmet Akif Ersoy Üniversitesi, Mühendislik Mimarlık Fakültesi, Burdur \\ ${ }^{2}$ Burdur Mehmet Akif Ersoy Üniversitesi, Gölhisar Meslek Yüksekokulu, Burdur \\ Geliş Tarihi (Received): 29.04.2021, Kabul Tarihi (Accepted): 07.07.2021 \\ $\square$ Sorumlu Yazar (Corresponding author*): sgorgulu@mehmetakif.edu.tr \\ (C) +902482132771 杬 +902482132704
}

\section{ÖZ}

Son birkaç on yılda ortaya çıkan enerjiyi tasarruflu ve verimli kullanma terimleri her alanda karşımıza çıkmaktadır. Bu terimlerin karşımıza çıkmasındaki en önemli etkenlerden birisi özellikle hayatımızın vazgeçilmezi olan elektrik enerjisinin üretiminde kullanılan fosil yakıt kaynaklarının tükeniyor olması ve bunların çevreye olan olumsuz etkileridir. Bu olumsuz etkileri en aza indirmek ve daha yaşanılabilir bir dünya sağlamak için her alanda enerji tasarrufu ve verimliliği ön plana çıkmaktadır. Bu sebeplerle aydınlatma aygıtlarında da verimli ve tasarruflu cihazların kullanımı teşvik edilmektedir. Günümüzde aydınlatma için en çok kullandığımız lambalar tasarruflu lamba çeşitleridir. Flüoresan lambaların küçük hale getirilerek normal lamba duylarında kullanılabilen kompakt flüoresan lambalar (CFL) ve LED lambalar en çok tercih edilen aydınlatma ürünleridir. Bunlar arasında özellikle LED lambalar, son yıllarda kullanımı oldukça artan ve diğer yapay ışık kaynaklarına göre daha verimli olan lambalardır. Ticari olarak birçok firma tarafından üretilen ve tüketicilerin kullanımına sunulan LED lambalar aydınlatma özellikleri, elektriksel özellikler ve ömür olarak muadil lambalar arasında öne çıkmaktadır. Bu çalışmanın amacı E27 duya sahip LED lambaların ve diğer lambaların elektrik ve ışık özelliklerinin, ömürlerinin ve verimliliklerinin karşılaştırılması için test düzeneğinin hazırlanması ve örnek uygulamanın yapılmasıdır.

Anahtar Kelimeler: Aydınlatma, E27, enerji tasarrufu, LED lambalar

\section{Preparation of Test System to Compare the Lamps with E27 Sockets}

\section{ABSTRACT}

The terms such as energy saving and efficient energy use that emerged in the last few decades appear in every field. One of the most important factors in the emergence of these terms is the depletion of fossil fuel resources used in the production of electrical energy, which is an indispensable part of our lives, and its negative effects on the environment. To minimize these negative effects and provide a more livable world, energy saving and efficiency come to the fore in every field. For these reasons, the use of efficient and economical devices in lighting devices is encouraged as well. The lamps we use the most for lighting today are energy saving lamp types. Compact fluorescent lamps and LED lamps, which can be used in normal lamp bases by making fluorescent lamps small, are the most preferred lighting products. Among these, especially LED lamps, are lamps that have increased in use in recent years and are more efficient than other artificial light sources. LED lamps, which are commercially produced by many companies and offered to consumers, stand out among equivalent lamps in terms of illumination properties, electrical properties, and lifetime. This study aims to prepare a test setup and make a sample application to compare the electrical and luminous features, lifetime, and efficiency of LED lamps with an E27 socket and other lamps.

Keywords: Lighting, E27, energy savings, LED 


\section{GíRiş}

Günümüzde küresel ısınma insanlığın geleceğini tehdit eden sorunların başında gelmektedir. Küresel ısınmanın başlıca sebeplerinden birisi de enerji üretiminde kullanılan fosil kaynaklı yakıtların yanması ile ortaya çıkan sera gazlarıdır. Sera gazı emisyonlarının azaltılması için yenilenebilir enerji kaynaklarından enerji üretimine ağırlık verilmesi ve üretilen enerjinin verimli olarak kullanılması dünyamızın geleceği açısından önemlidir. Birçok ülke sera gazı emisyonlarının düşürülmesi için aydınlatmada enerji verimliliği ve tasarrufunu da içeren çeşitli stratejiler geliştirmektedir (Ardavani ve ark., 2020). 2020 Avrupa Birliği Strateji belgesinde enerji verimliliğinin \%20 arttırılması, sera gazı emisyonlarının \%20 azaltılması ve Avrupa birliği genelinde enerji tüketiminin \%20'sinin yenilenebilir enerjiden sağlanması hedeflenmektedir (Radulovic ve ark., 2011; Lazaroiu ve Roscia, 2012). Amerika Birleşik Devletleri Enerji Bakanlığı'na göre; aydınlatma, dünyadaki sera gazı emisyonlarının yaklaşık \%5'ini oluşturmaktadır (Görgülü ve Kocabey, 2020). Dünyada aydınlatma için tüketilen enerji toplam enerji tüketiminin yaklaşık \%20'sini oluşturmaktadır (Doğru ve ark., 2021).

Modern toplumlar için aydınlatma vazgeçilmez bir intiyaçtır. Bu vazgeçilmez unsurun kullanımında da yukarıda belirtilen sebeplerden ötürü tasarruf yapılması oldukça önemlidir. Aydınlatma; binalardaki enerji tüketimini oldukça etkilemektedir (Şahin ve ark., 2014). Aydınlatmadaki enerji tasarrufu, aydınlatma kalitesi düşürülmeden ve iyi aydınlatmanın şartları sağlanarak yapılmalıdır. Daha verimli aydınlatma elemanları kullanılmasıyla, daha az enerji tüketimiyle aynı aydınlatma düzeyi sağlanabilir. Aydınlatma sistemlerinde yapılacak iyileştirmelerle bina işletme maliyetlerinde yaklaşık $\% 10$ azalma ve \%30 civarında da enerji tasarrufu sağlanabilir (Yılmaz ve Sungur, 2020).

2015 yılında yapılan bir çalışmada; Avrupa Birliği genelinde 18 milyon lambanın, daha verimlileri ile değiştirilmesinin beklendiği belirtilmektedir (Tähkämö ve ark., 2015). Bu bağlamda pek çok ülke akkor flamanlı lambaların kullanımını kademeli olarak kaldırmaya başlamıştır (Khorasanizadeh ve ark., 2016). Ayrıca bu kapsamda Avrupa Birliği Nisan 2017'de düşük enerji verimliliğine sahip lambaların daha verimli olanlar ile değiştirilmesi ilgili düzenlemeyi yürürlüğe almıştır (Görgülü ve Kocabey, 2020). Avrupa Birliği; $\mathrm{CO}_{2}$ emisyonlarının azaltılması konusundaki programlarında, kamuda kullanılan aydınlatma sistemlerinde yüksek verimli teknolojilerin kullanılmasını benimsemiştir (Brandoni ve Polonara, 2012; Beccali ve ark., 2015;
Campisi ve ark., 2018). Yukarıda verilen bilgiler ışığında enerjinin verimli olarak kullanılması aydınlatmada da önemli bir yere sahip olduğu anlaşılmaktadır.

Bu çalışmanın amacı; son kullanıcı tarafından yoğun olarak kullanılan E27 duya sahip lambaların çalışma sıcaklığı, kullandıkları akım ve gerilim değerleri ile aydınlık seviyelerinin karşılaştırılmasını sağlayacak bir test sistemi oluşturmaktır. Böylelikle testi gerçekleştirilen lambaların nitelik ve nicelik yönünden karşılaştırmaları yapılabilecektir. Firmaların katalog verileri ile gerçek uygulama sonuçları değerlendirilebilecektir.

\section{MATERYAL VE YÖNTEM}

Çalışma kapsamında tasarlanan ölçüm sistemi Burdur Mehmet Akif Ersoy Üniversitesi Fen - Edebiyat Fakültesi Dekanlığı tarafından tahsis edilen odaya kurulmuştur. Ölçüm sisteminde kullanılan bileşenlerin ayrıntıları aşağıda sunulmuştur.

Hazırlanan test düzeneği üç bölgeden oluşmaktadır. Alttaki iki kısım iki farklı lambanın test edilmesine olanak sağlayan montaj kısmı, üst kısım elektriksel bağlantıların olduğu kısımdır. Ölçümü yapılacak olan lambalar ilgili bölmeye yerleştirilerek ölçümler alınmıştır. Sistem içerisine dışarıdan ışık girmeyecek şekilde hazırlanmıştır. Kurulan ölçüm sistemindeki test düzeneği Şekil 1'de görülmektedir.

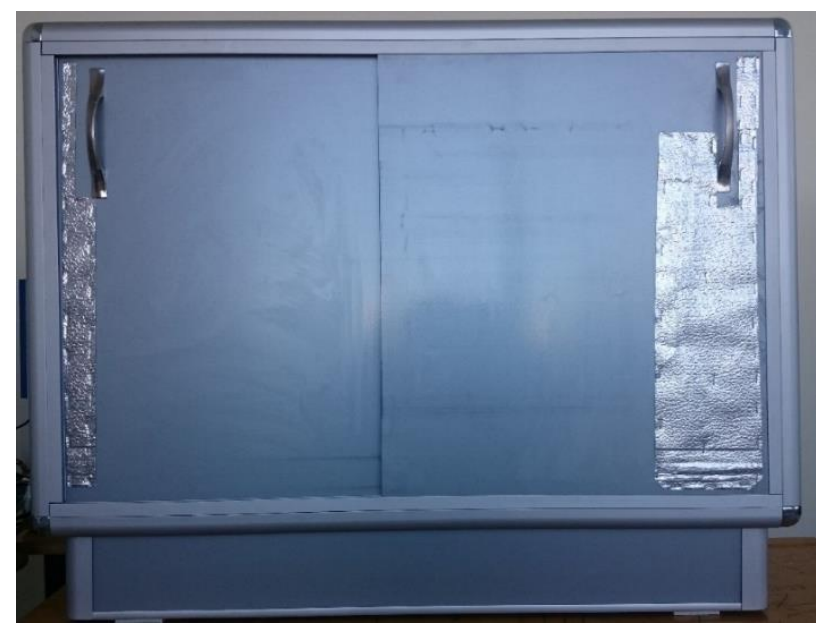

Şekil 1. Test düzeneğinin görünümü

Lambaların enerji değerlerinin ölçümü, karşılaştırılması ve kayıt altına alınması için Şekil 2'de görülen ENTES marka MPR63-41 serisi enerji analizörü kullanılmıştır. Cihaz; bir elektrik şebekesine ait tüm parametreleri belirlenen zaman aralığında ölçmek ve kaydetmek amacıyla tasarlanmış dijital sinyal işleme tabanlı üniversal bir cihazdır. Ölçülen parametreler 3,6 
E27 Duya Sahip Lambaların Karşılaştırması İçin Test Düzeneği Hazırlanması

inçlik LCD ekranda görüntülenmekte ve içerisinde buIunan hafıza birimlerine kaydedilmektedir. Cihaz MODBUS seri haberleşme ara yüzüne sahiptir. RS-485 endüstriyel bağlantısını kullanarak diğer cihazlarla ve bilgisayar ile veri alışverişi yapabilmektedir (URL-1, 2021). Pano tipi ölçü aleti olduğundan test düzeneğine montajı yapılmıştır.

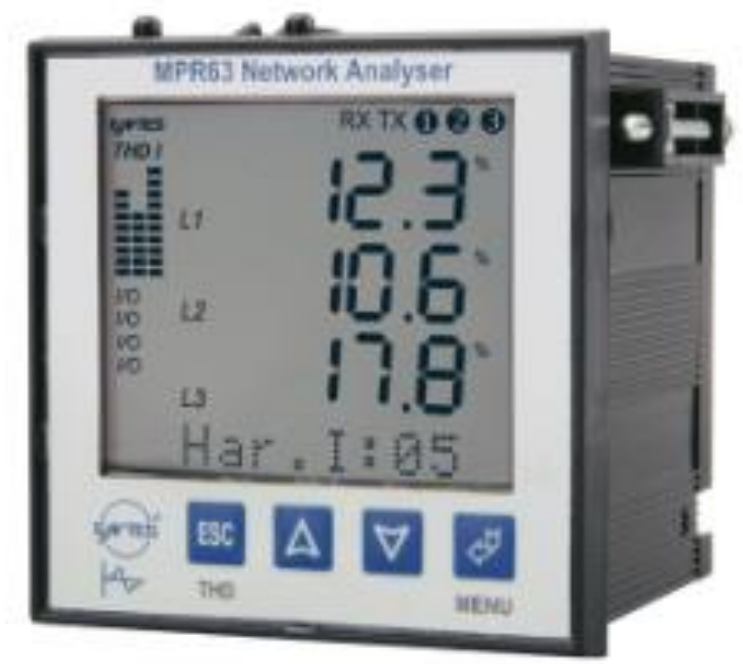

Proje kapsamında lambaların ısıl değerlerini okumak için FLIR markasının E6 model termal kamerası alınmıştır. 3" 320 x 240 renkli ekrana sahip bu kameranın detektör çözünürlüğü 160 x 120 piksel, MSX çözünürlüğü $320 \times 240$ piksel, termal hassasiyeti $0,06^{\circ} \mathrm{C}$ ve sıcaklık ölçüm aralığı -20 ile $+250^{\circ} \mathrm{C}$ 'dir. Termal kameranın genel özellikleri Tablo 1'de verilmiştir. Termal kamera Şekil 3'de görülmektedir.

Şekil 2. Enerji analizörü

Tablo 1. Termal kamera özellikleri

\begin{tabular}{|c|c|}
\hline Görüş Alanı / Odak mesafesi & $45^{\circ} \times 34^{\circ} / 0,5 \mathrm{~m}$ \\
\hline Spektral Aralık & $7,5-13 \mu \mathrm{m}$ \\
\hline Frekans & $9 \mathrm{~Hz}$ \\
\hline Odaklama & Serbest Odak \\
\hline Detektör Tipi & Soğutmasız Mikrobolometre \\
\hline Ekran & 3" 320 x 240 Renkli LCD \\
\hline Sıcaklık Öıçüm Aralığı & $-20^{\circ} \mathrm{C}$ ile $+250^{\circ} \mathrm{C}$ \\
\hline Doğruluk & $\begin{array}{l} \pm 2^{\circ} \mathrm{C} \text { veya } \pm \% 2 \text {, çevre sıcaklığı } 10^{\circ} \mathrm{C} \text { 'den } 35^{\circ} \mathrm{C} \text { 'ye ve objenin sıcaklığı } \\
+0^{\circ} \mathrm{C} \text { üstü için }\end{array}$ \\
\hline Emisivite & 0,1 'den 1,0'e kadar ayarlanabilir \\
\hline Emisivite tablosu & Tanımlı malzemeler için emisivite tablosu \\
\hline Renk Paletleri & Demir, Gökkuşağı ve Siyah/Beyaz \\
\hline Görüntü Depolama Seçenekleri & Dâhili hafıza içerisine IR/Gerçek görüntü setlerinden 500 adet \\
\hline Dosya Formatı & Radyometrik JPEG \\
\hline Ara yüz & PC veya Mac cihazınıza veri transferi için Mikro USB \\
\hline Pil / Pil Ömrü & Şarj edilebilir Lityum İyon Pil / 4 saat \\
\hline Şarj Sistemi ve Süresi & USB Mikro çıkışı ile PC veya şarj adaptöründen / 2,5 saat \\
\hline Çalışma Sıcaklığı & $-15^{\circ} \mathrm{C}-+50^{\circ} \mathrm{C}$ \\
\hline Depolama Sıcaklığı & $-40^{\circ} \mathrm{C}-+50^{\circ} \mathrm{C}$ \\
\hline Çalıştığı Bağıl Nem & $\% 95$ \\
\hline (IP) değeri / Titreşim/ Darbe & IP54 / 25G / 2G \\
\hline Boyut ve Ağırlık & $244 \times 95 \times 140 \mathrm{~mm}, 575 \mathrm{~g}$ (pil ile) \\
\hline
\end{tabular}




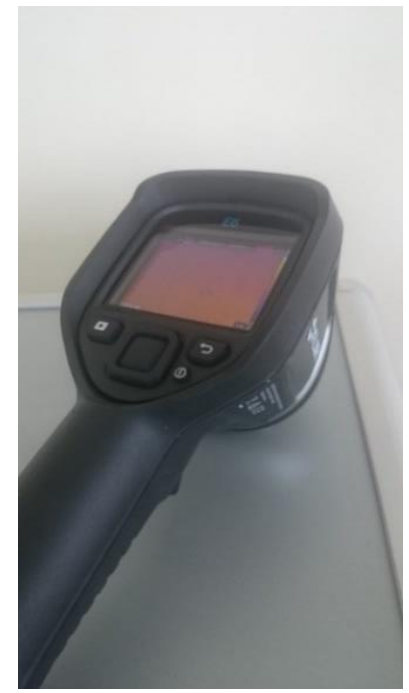

Şekil 3. Termal kamera

Proje kapsamında lambaların aydınlık düzeylerini ölçmek için EXTECH markasının SDL 400 modeli ışıkölçeri (lüksmetre) alınmıştır. Bu cihaz 100 kLux'e kadar aralığa göre değişen çözünürlükte ölçüm yapabilen $\pm \% 4$ hassasiyete sahiptir. Şekil 4'de ışıöllçer görülmektedir. Işıölçerin özellikleri Tablo 2'de verilmiştir.

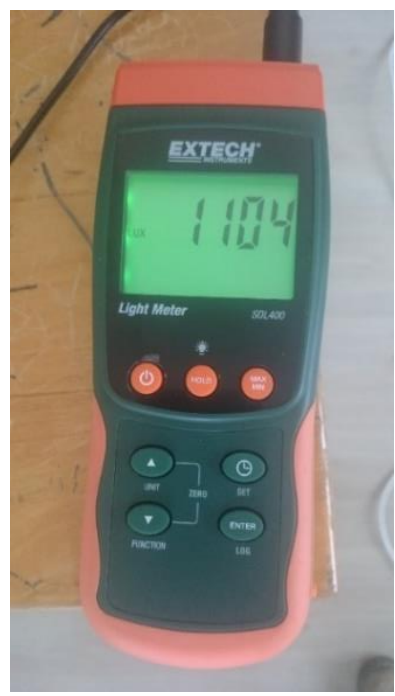

Şekil 4. Işıkölçer

Test edilecek lambaların karakteristik değerlerini ölçüp karşılaştırma yapma imkânı sağlayacak sistemin blok şeması Şekil 5'te görülmektedir. Bu şekle uygun olarak yapılan kablolama ile sistem bileşenleri ölçüm alacak şekilde hazır hale getirilmiştir.

Tablo 2. Işıkölçer özellikleri

\begin{tabular}{|c|c|c|}
\hline Aralık & Çözünürlük & Doğruluk \\
\hline 2,000 LUX & $1 \mathrm{LUX}$ & \multirow{4}{*}{$\pm(\% 4 r d g+2 d g t)$} \\
\hline 20,000 LUX & $10 \mathrm{LUX}$ & \\
\hline 100,000 LUX & 100 LUX & \\
\hline $200 \mathrm{Ft}-\mathrm{cd}$ & $0,1 \mathrm{Ft}-\mathrm{cd}$ & \\
\hline $2,000 \mathrm{Ft}-\mathrm{cd}$ & $1 \mathrm{Ft}-\mathrm{cd}$ & $\pm(\% 4 \mathrm{rdg}+2 \mathrm{Ft}-\mathrm{cd})$ \\
\hline $10,000 \mathrm{Ft}-\mathrm{cd}$ & $10 \mathrm{Ft}-\mathrm{cd}$ & $\pm(\% 4 \mathrm{rdg}+20 \mathrm{Ft}-\mathrm{cd})$ \\
\hline Ekran & \multicolumn{2}{|c|}{$52 \times 38 \mathrm{~mm}$ LCD $\left(2 \times 1,5^{\prime \prime}\right)$} \\
\hline Veri örnek aralığı & \multicolumn{2}{|l|}{$1-3600 \mathrm{sn}$} \\
\hline Hafıza Kartı & \multicolumn{2}{|l|}{ SD 1-16 GB } \\
\hline Veri çıkışı & \multicolumn{2}{|c|}{$R S-232 / U S B$} \\
\hline Çalışma sıcaklığı & \multicolumn{2}{|l|}{$0-50^{\circ} \mathrm{C}$} \\
\hline Çalıştığı bağıl nem & \multicolumn{2}{|l|}{ Mak. \%95 } \\
\hline Ağırlık & \multicolumn{2}{|l|}{$346 \mathrm{~g}$} \\
\hline Boyut & \multicolumn{2}{|c|}{$182 \times 73 \times 47,5 \mathrm{~mm}$} \\
\hline
\end{tabular}




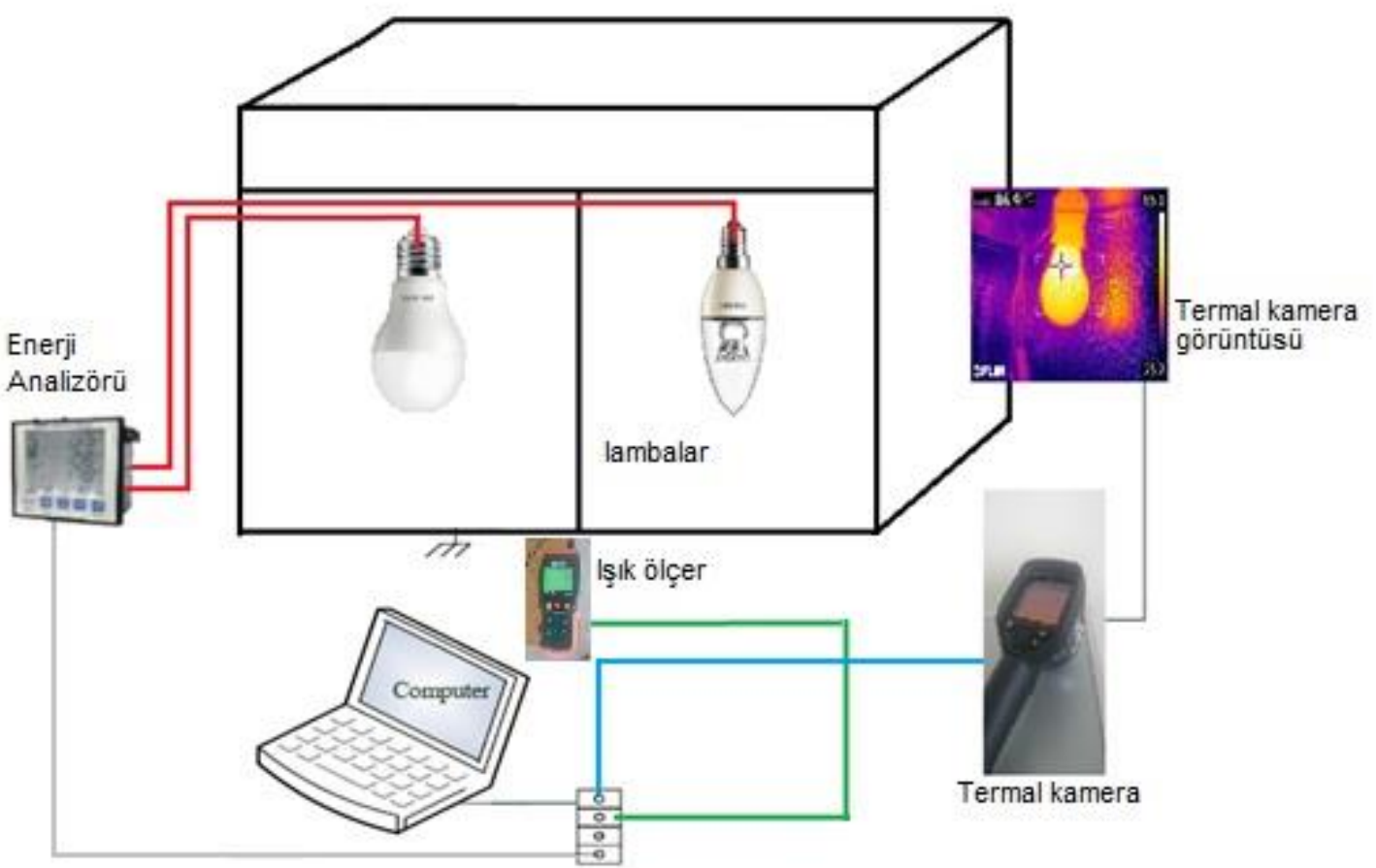

Şekil 5. Tasarlanan sistemin blok şeması

Yukarıdaki blok şemaya uygun aşağıdaki Şekil 6'da resmi görülen düzenek yapılarak gerekli montajlar yapılmıştır. E27 duya sahip olan tüm lambaların karşılaştırmasının yapılabileceği şekilde sistem tasarımı gerçek- leştirilmiştir. Tasarıma uygun olarak test sistemi hazırlandıktan sonra uygulama için piyasada kolaylıkla bulunan ve önde gelen firmalardan olan bir markanın iki adet lambası test düzeneğine bağlanarak test edilmiştir.

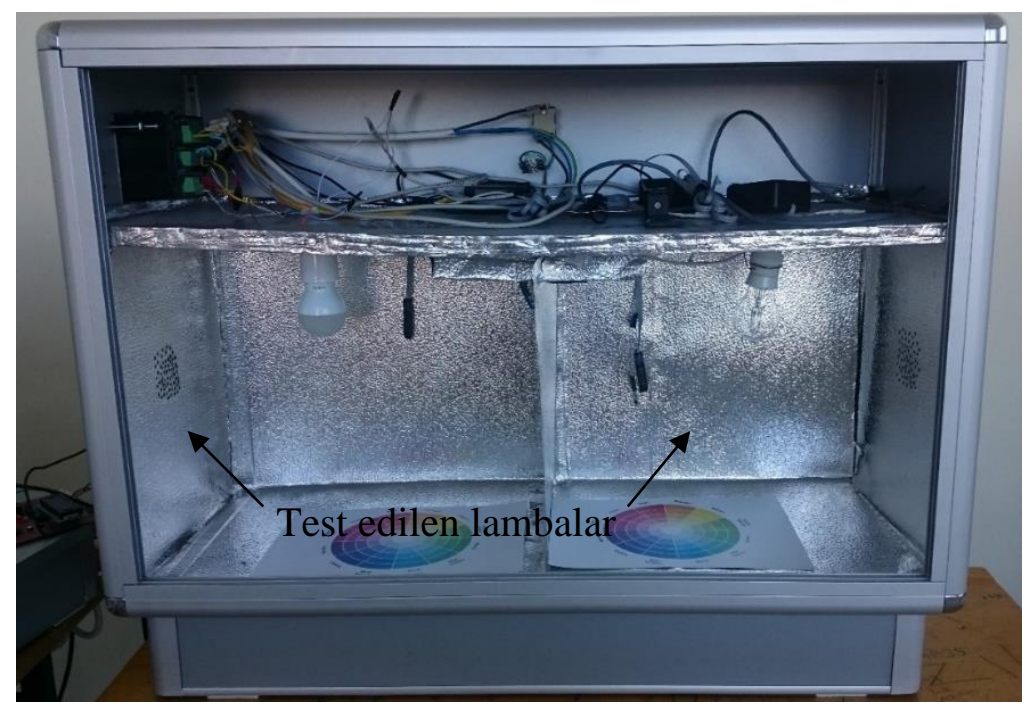

Şekil 6. Hazırlanan test düzeneği

Test aşaması için öncelikle lambaların montajı yapılmıştır. Test sırasında diğer ışık kaynaklarının ölçüm siste- mini etkilememesi için kapakları monte edilmiştir. Elektriksel değerler test düzeneğine monte edilen enerji ana- 
lizörü ile aydınlık düzeyi yukarıda tanıtımı yapılan ve dışarıdan ışık girmesini önleyecek şekilde ışıkölçer ile ve lamba sıcaklıkları ise termal kamera ile ölçülmüştür.

Karşılaştırması yapılacak lambaların aydınlık düzeyi ve sıcaklık değerleri harici olarak ışıkölçer ve termal kamera ile ölçülerek manuel olarak bilgisayara yüklenmiştir. Akım, gerilim, güç, frekans, faz farkı gibi değerler test sistemine monte edilen güç analizörü ile ölçülmekte ve bilgisayara otomatik olarak aktarılmaktadır. Elektriksel veriler 24 saat boyunca 5 dakikalık aralıklarla alınırken, sıcaklık ve aydınlık düzeyi değerleri saatlik olarak alınmıştır. Ölçüm halindeki sistemin görünümü Şekil 7'de verilmiştir.

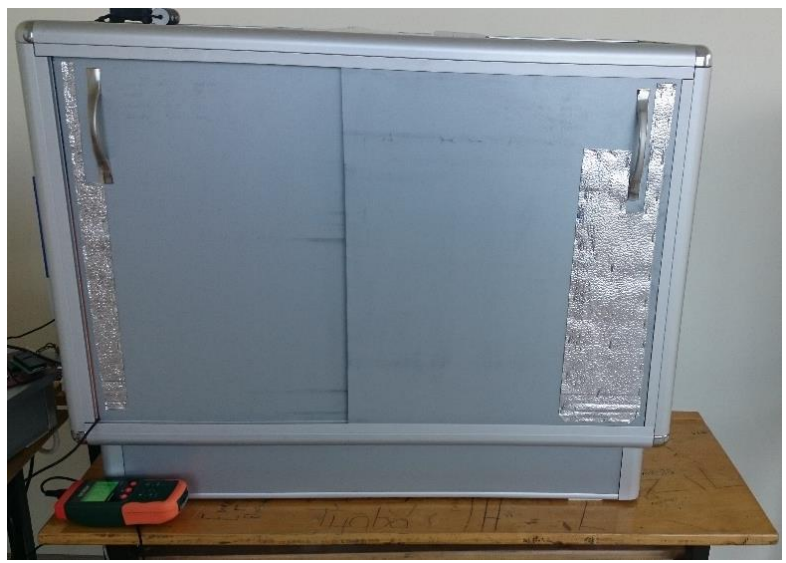

Şekil 7. Ölçüm anında test düzeneğinin görünümü

Enerji analizörünün 5 dakikada bir kaydettiği verilerin bilgisayara aktarımasında kullanılan programın veri aktarımı sırasındaki görüntüsü Şekil 8'de görülmektedir.
Analizörde kaydedilen tüm veriler analizörün kendi programı ile bilgisayar ortamına aktarılmıştır.

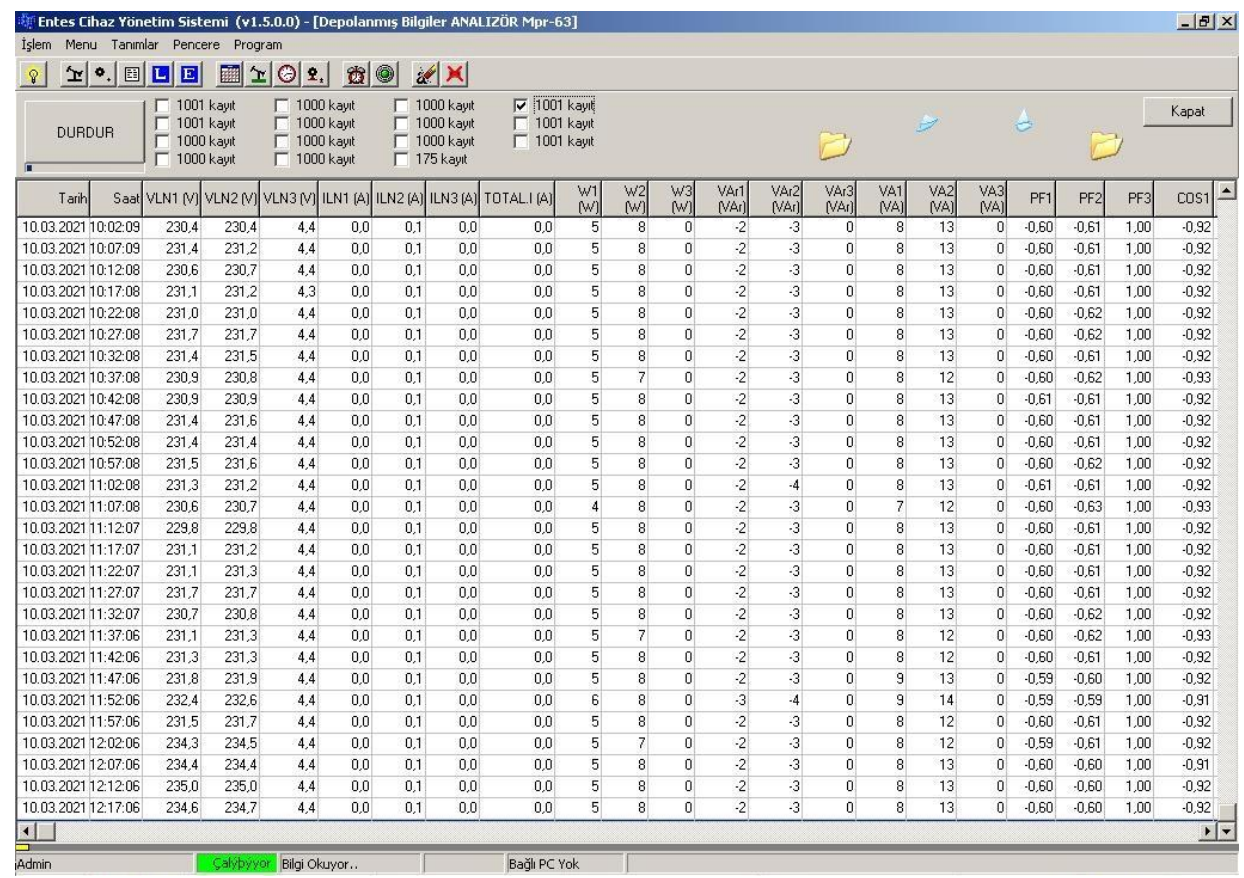

Şekil 8. Güç analizörü veri aktarım programı 


\section{BULGULAR VE TARTIŞMA}

Yukarıda belirtilen yöntemler ile iki farklı lamba (CFLLED) 28 hafta boyunca test havuzunda sürekli olarak çaIıştırılmıştır. Bu süre boyunca CFL lamba iki defa (9. ve 20. Hafta) arızalanmış ve yenisi ile değiştirilmiştir. Lambaların değiştiği anlar Şekil 9'da görülebilir. Ayrıca, grafik incelendiğinde LED lambaların aydınlık düzeyi değerlerinin CFL'lere göre daha az dalgalandığı görülmüştür. Bunun yanında lambaların aydınlık düzeylerinin eğimleri karşılaştırıldığında CFL lambalarda çok az bir azalma görülmüştür. Yaşlandırma ve uzun süreli ölçümlerde bu değerin hesaplanması için daha uygun olacağı düşünülmüştür. Bunun yanında grafikte görüleceği üzere LED lambaların çok azda olsa daha az ışık kaybı gösterdiği ve daha düzgün aydınlık değerlerine sahip olduğu değerlendirilmiştir. Grafik CFL aydınlık düzeyi ve dayanıklılık açısından LED lambalara göre bariz şekilde geride kaldığını göstermektedir.

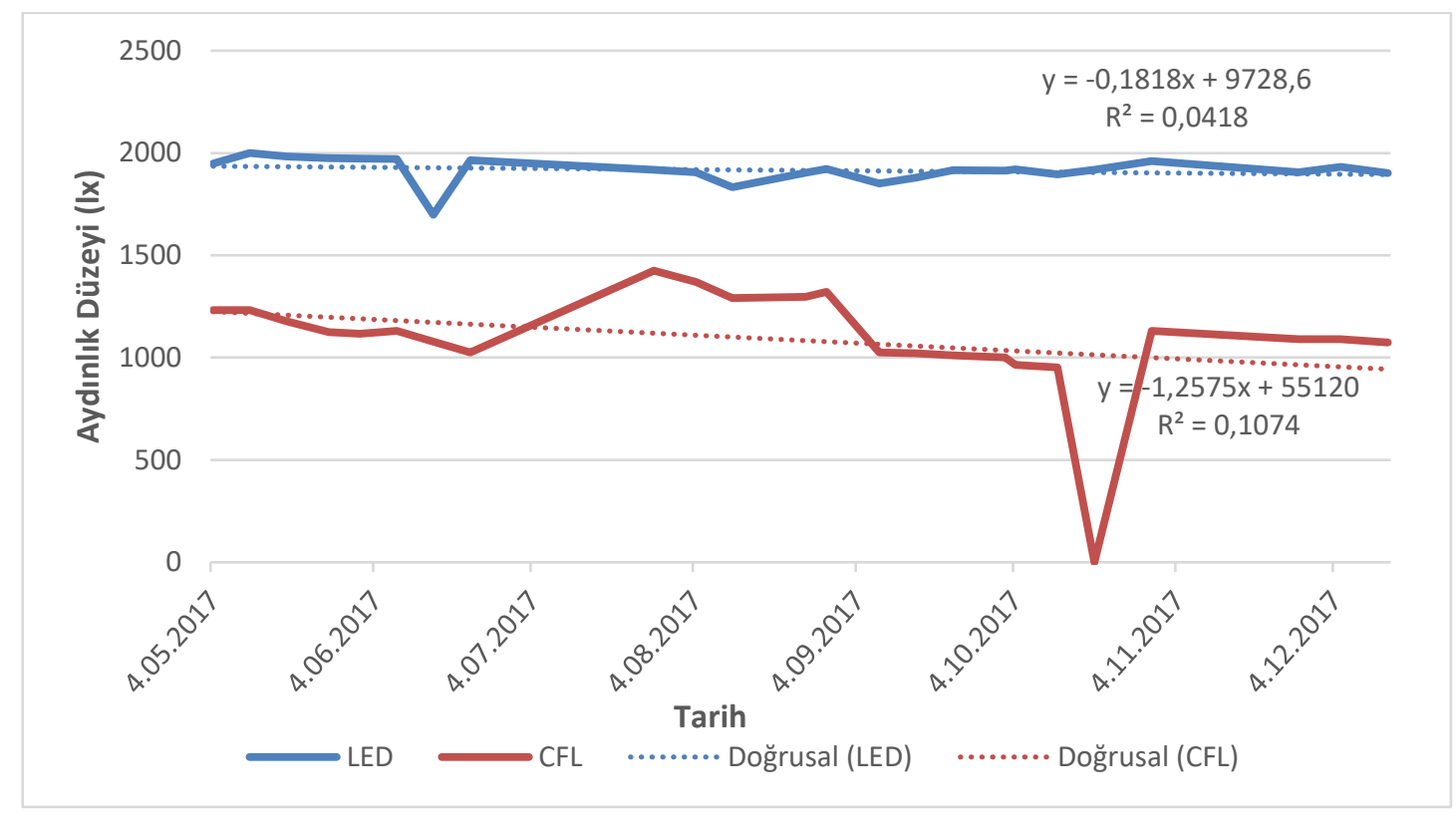

Şekil 9. Lambaların aydınlık düzeyleri ve arızalanma zamanları

Şekil 10'da a tasarruflu lambanın, b ise LED lambanın termal kamera ile alınan görüntüleri görülmektedir. Termal kamera görüntüsünde odak noktasındaki maksimum sıcaklık ve görüntüsü alınan ortamdaki sıcaklık aralığı renk ayrımıyla görünmektedir. Bu ölçümlerde oda sıcaklığında çalışmakta olan lambalardan özellikle tasarruflu olan lambanın daha fazla ısı ürettiği görülmektedir. Şekil 11'de a kompakt flüoresan lambanın (CFL), $b$ ise LED lambanın termal kamera ile alınan görüntüleri görülmektedir. Bu ölçümlerde oda sıcaklığında çalışmakta olan lambalardan özellikle CFL'nin daha fazla ISı ürettiği görülmektedir. CFL'nin fazla ısı üretmesi içerdiği elektronik bileşenlerin ömrünün kısalmasında ve doğal olarak lambanın daha çabuk arızalanarak devre dışı kalmasında etken olduğu değerlendirilmiştir. Bunun yanında deney süresince LED lambanın hiç arızalanmaması buna rağmen CFL lambanın iki defa arızalanarak kullanılamaz hale gelmesi ısı ile ilişkilendirilmiştir. 


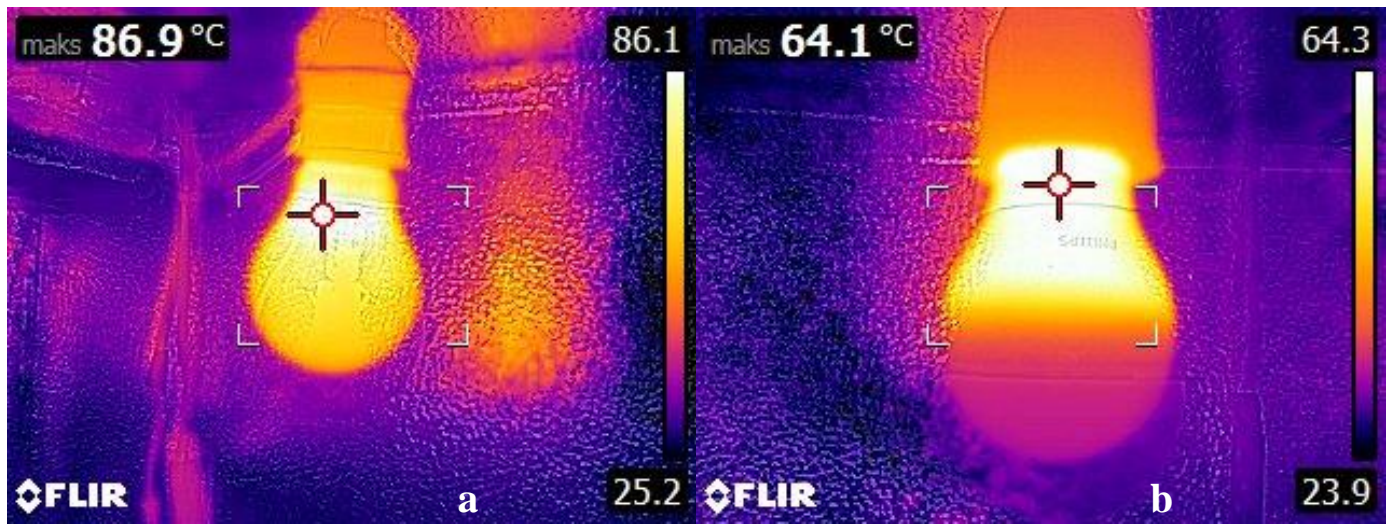

Şekil 10. Termal kamera görüntüleri; a) Tasarruflu lamba, b) LED lamba

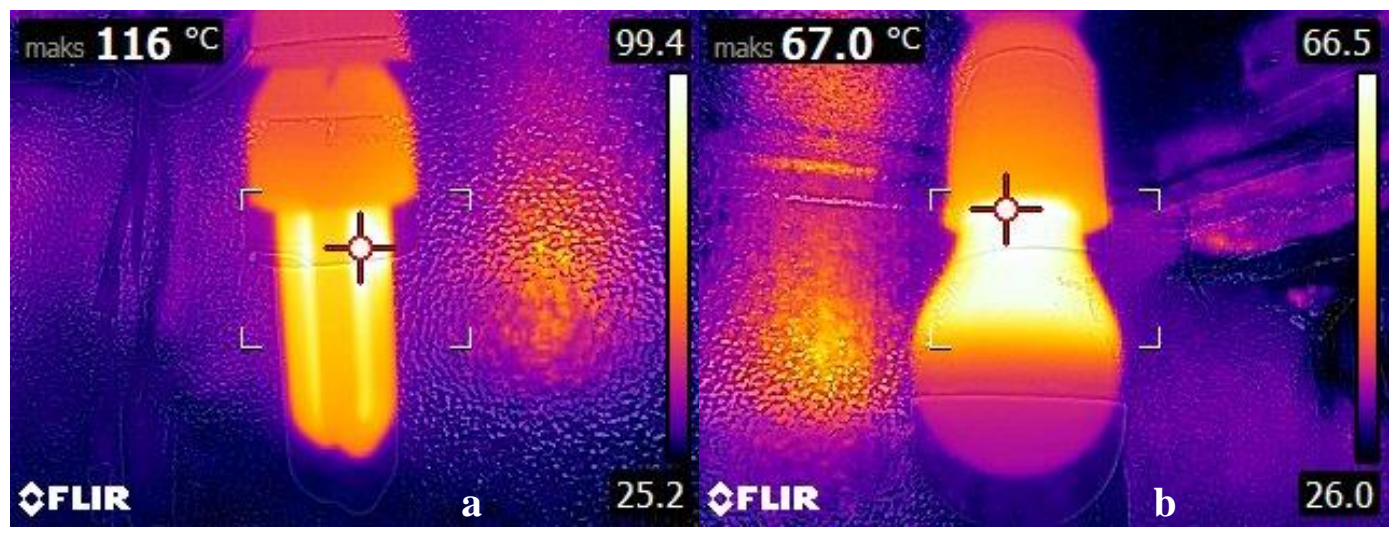

Şekil 11. Termal kamera görüntüleri; a) CFL lamba, b) LED lamba

Işıkölçer (lüksmetre) kullanılarak yapılan ölçüm sonuçları Şekil 12'de gösterilmiştir. Grafikte CFL lambanın arızaları grafik düzeni için normalize edilmiştir. Grafik incelendiğinde LED lambaların aydınlık düzeyi değerlerinin CFL’lere göre daha az dalgalandığı görülmüştür. Bunun yanında lambaların aydınlık düzeylerinin eğimleri karşılaştırıldığında CFL lambalarda çok az bir azalma görülmüştür. Yaşlandırma ve uzun süreli ölçümlerde bu değerin hesaplanması için daha uygun olacağı düşünülmüştür. Bunun yanında grafikte görüleceği üzere LED lambaların çok azda olsa daha az ışık kaybı gösterdiği ve daha düzgün aydınlık değerlerine sahip olduğu değerlendirilmiştir. Yine aşağıdaki grafik için üç farklı CFL kullanıldığı ve buna rağmen aydınlık düzeyi değerinin azaldığına ayrıca dikkat edilmelidir. Sadece bu grafik CFL aydınlık düzeyi ve dayanıklılık açısından LED lambalara göre bariz şekilde geride kaldığını göstermektedir.

Enerji analizörü ile birçok veri kaydedilmiş olup CFL'nin arızalandığı değerler normalize (arızalanma anı değerleri grafikten çıkartılmıştır) edilmiştir. Bunun ile birlikte iki lamba için görünür güç, akım ve güç faktörü değerlerinin grafikleri sırasıyla Şekil 12, Şekil 13 ve Şekil 14'de görülmektedir. 
E27 Duya Sahip Lambaların Karşılaştırması İçin Test Düzeneği Hazırlanması

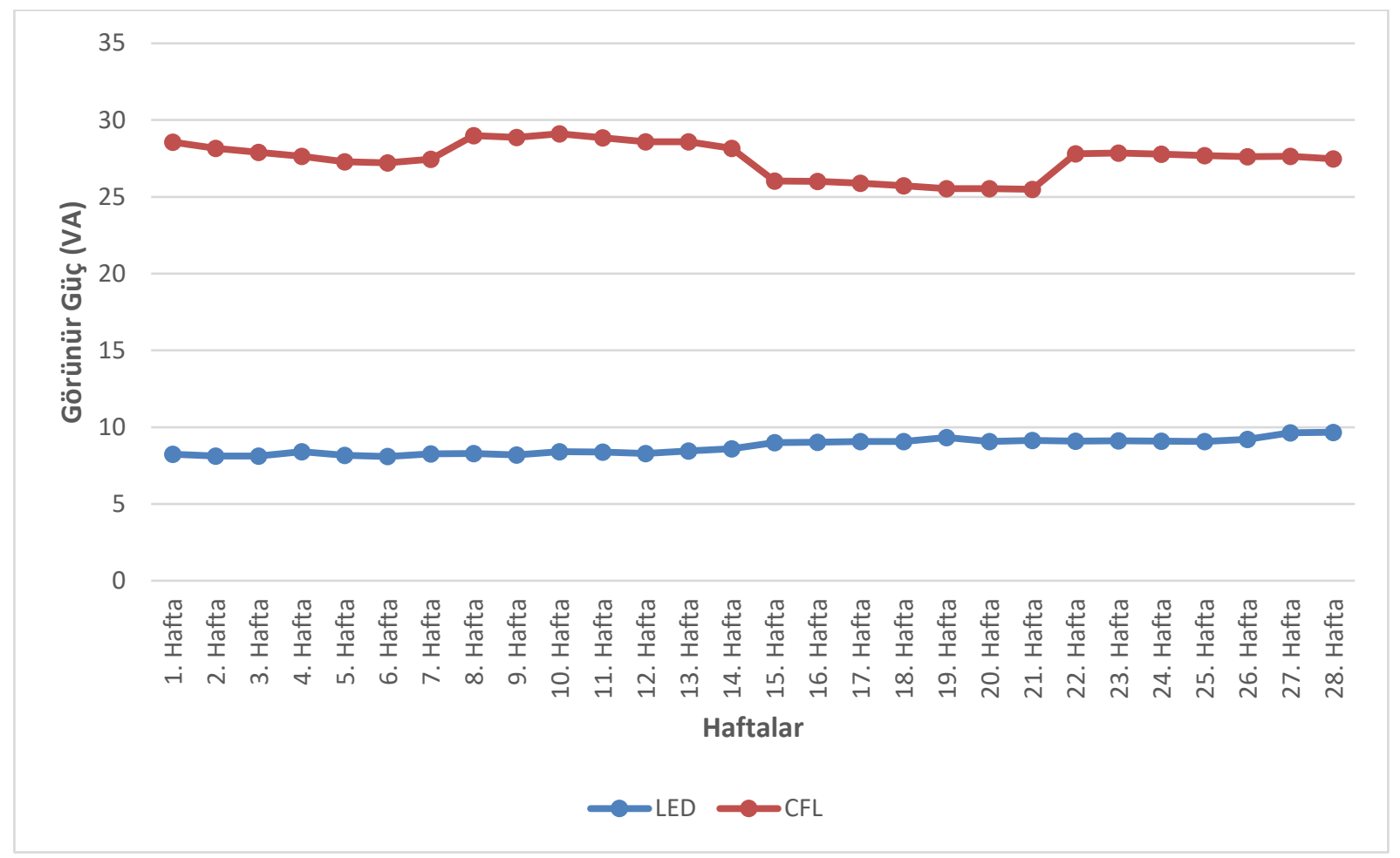

Şekil 12. Görünür Güç Grafiği

0,14

0,12

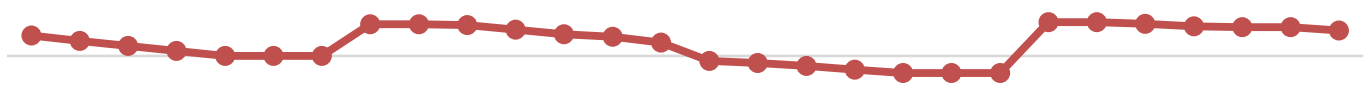

0,1

¿ 0,08

产 0,06

0,04

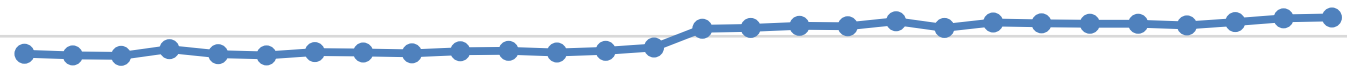

0,02

0

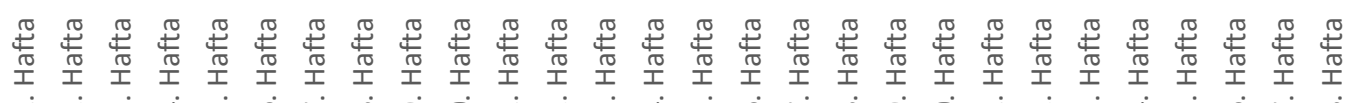

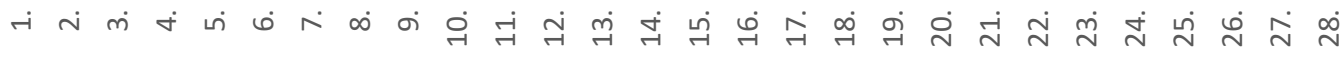

$$
\begin{aligned}
& \text { Haftalar } \\
& \longrightarrow \text { LED } \longrightarrow \text { CFL }
\end{aligned}
$$

Şekil 13. Akım Grafiği 


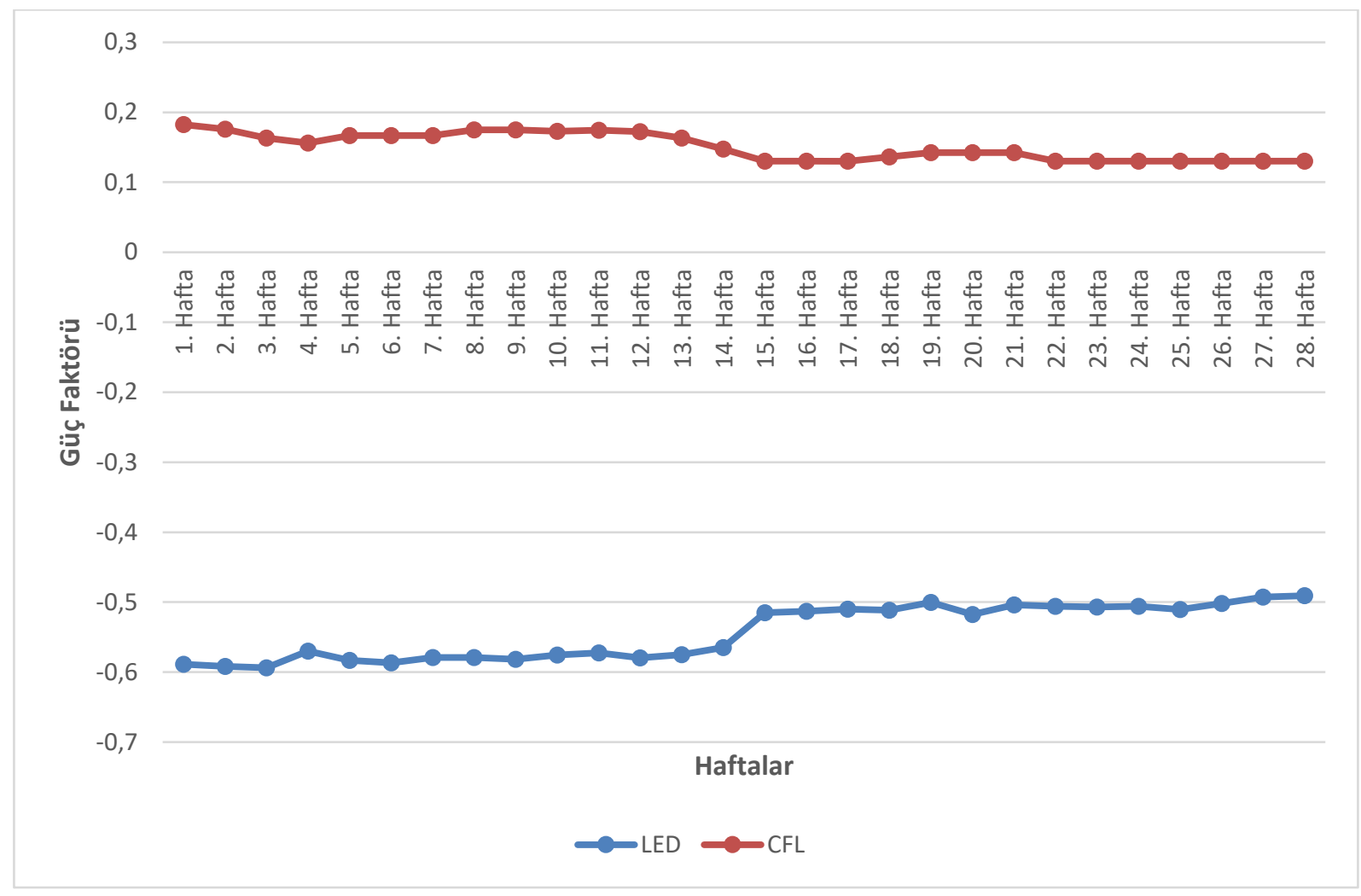

Şekil 14. Güç Faktörü Grafiği

Yukarıdaki elektriksel veriler değerlendirildiğinde LED lambanın elektriksel karakteristiğinin ve güç değerlerinin CFL lambalara göre daha düzenli ve kararlı olduğu görülmüştür. Bu sayede ömür ve aydınlık düzeyi değerlerinin olumlu yönde etkilendiği değerlendirilmiştir.

\section{SONUÇLAR}

Dünya genelinde artan talebe bağlı olarak yeni enerji kaynağı arayışları devam etmektedir. Bununla birlikte enerji tasarrufu konusunda yapılan çalışmalar, yeni enerji kaynağı bulmak kadar büyük öneme sahiptir. Bu çalışma ile aydınlatma enerjisinde tasarruf yapabilmek için kullanılması düşünülen lambaların verimliliklerinin, kullanım ömürlerinin ve sağladığı aydınlık düzeylerinin karşılaştırmalı olarak test edilmesine olanak sağlayan bir test düzeneği oluşturulmuştur. Böylece tasarruf yapılması istenilen ortama göre lambalar test edilerek en verimli olan lambanın kullanımı sağlanabilecektir.

\section{TEŞEKKÜR}

Bu çalışma; 0319-NAP-16 numaralı proje kapsamında Burdur Mehmet Akif Ersoy Üniversitesi Bilimsel Araştırma Projeleri Komisyonu tarafından desteklenmiştir.

\section{KAYNAKLAR}

Ardavani, O., Zerefos, S., Doulos, L.T. (2020). Redesigning the exterior lighting as part of the urban landscape: The role of transgenic bioluminescent plants in Mediterranean urban and suburban lighting environments. Journal of Cleaner Production, 242: 118477; https://doi.org/10.1016/j.jclepro.2019.118477.

Beccali, M., Bonomolo, M., Ciulla, G., Galatioto, A., Lo Brano, V. (2015). Improvement of energy efficiency and quality of street lighting in South Italy as an action of sustainable energy action plans. The case study of Comiso (RG). Energy, 92: 394-408.

Brandoni, C., Polonara, F. (2012). The role of municipal energy planning in the regional energy planning process. Energy, 48: 323-338.

Campisi, D., Gitto, S., Morea, D. (2018). Economic feasibility of energy efficiency improvements in street lighting systems in Rome. Journal of Cleaner Production, 175: 190198.

Doğru, A., Koymat, N., Civelek, Z. (2021). Ticari Bina LED Aydınlatma Sistemlerinde Enerji Tasarrufu İçin Bulanık Mantık Denetleyicisi. Uluslararası Mühendislik Araştırma ve Geliştirme Dergisi, 13(1): 22-31.

Görgülü, S., Kocabey, S. (2020). An energy saving potential analysis of lighting retrofit scenarios in outdoor lighting systems: A case study for a university campus. Journal of 
E27 Duya Sahip Lambaların Karşılaştırması İçin Test Düzeneği Hazırlanması

Cleaner Production, 260: 121060. https://doi.org/10.1016/j.jclepro.2020.121060.

Khorasanizadeh, H., Honarpour, A., Sang-Ah Park, M., Parkkinen, J., Parthiban, R. (2016). Adoption factors of cleaner production technology in a developing country: energy efficient lighting in Malaysia Journal of Cleaner Production, 131: 97-106.

Lazaroiu, G.C., Roscia, M. (2012). Definition methodology for the smart cities. Energy, 47: 326-332.

Radulovic, D., Skok, S., Kirincic, V. (2011). Energy efficiency public lighting management in the cities. Energy, 36: 19081915.

Şahin, M., Büyüktümtürk, F., Oğuz, Y. (2014). Karma ve Yarı Endirekt Aydınlatma Türlerinin Teknik ve Ekonomik Yönden Karşılaştırılması. BAÜ Fen Bilimleri Enstitüsü Dergisi, 16(2): 26-38.
Tähkämö, L., Räsänen, R.S., Halonen, L. (2015). Life cycle cost comparison of high-pressure sodium and light-emitting diode luminaires in street lighting. The International Journal of Life Cycle Assessment, 21(2): 137-145.

URL-1 (2021). https://www.entes.com.tr/uploads/files/MPR63_MPR-63-10-20-21-40-41_Sebeke_Analizoru_Kullanma_Talimati_TR.pdf (Erişim Tarihi: 15/03/2021).

Yılmaz, S., Sungur, C. (2020). Kamu binalarında mevcut aydınlatma elemanlarının LED aydınlatma elemanlarına dönüştürülmesi ile elde edilecek elektrik enerjisi tasarrufunun belirlenmesi. Avrupa Bilim ve Teknoloji Dergisi, Özel Sayı: 214-218. 